NATIONAL LABORATORY

\title{
Influence of Heat Treatment on Mercury Cavitation Resistance of Surface Hardened 316LN Stainless Steel
}

September 2010

Prepared by

S. J. Pawel

J. C. Hsu

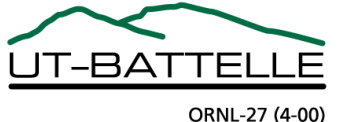




\section{DOCUMENT AVAILABILITY}

Reports produced after January 1, 1996, are generally available free via the U.S. Department of Energy (DOE) Information Bridge.

Web site http://www.osti.gov/bridge

Reports produced before January 1, 1996, may be purchased by members of the public from the following source.

National Technical Information Service

5285 Port Royal Road

Springfield, VA 22161

Telephone 703-605-6000 (1-800-553-6847)

TDD 703-487-4639

Fax 703-605-6900

E-mail info@ntis.gov

Web site http://www.ntis.gov/support/ordernowabout.htm

Reports are available to DOE employees, DOE contractors, Energy Technology Data Exchange (ETDE) representatives, and International Nuclear Information System (INIS) representatives from the following source.

Office of Scientific and Technical Information

P.O. Box 62

Oak Ridge, TN 37831

Telephone 865-576-8401

Fax 865-576-5728

E-mail reports@osti.gov

Web site http://www.osti.gov/contact.html

This report was prepared as an account of work sponsored by an agency of the United States Government. Neither the United States Government nor any agency thereof, nor any of their employees, makes any warranty, express or implied, or assumes any legal liability or responsibility for the accuracy, completeness, or usefulness of any information, apparatus, product, or process disclosed, or represents that its use would not infringe privately owned rights. Reference herein to any specific commercial product, process, or service by trade name, trademark, manufacturer, or otherwise, does not necessarily constitute or imply its endorsement, recommendation, or favoring by the United States Government or any agency thereof. The views and opinions of authors expressed herein do not necessarily state or reflect those of the United States Government or any agency thereof. 
Materials Science and Technology Division

\title{
INFLUENCE OF HEAT TREATMENT ON MERCURY CAVITATION RESISTANCE OF SURFACE HARDENED 316LN STAINLESS STEEL
}

\author{
S. J. Pawel \\ J. C. Hsu*
}

*Higher Education Research Experience Student,

Farragut High School, Knoxville, Tennessee.

Date Published: September 2010

Prepared by

OAK RIDGE NATIONAL LABORATORY

Oak Ridge, Tennessee 37831-6283

managed by

UT-BATTELLE, LLC

for the

U.S. DEPARTMENT OF ENERGY

under contract DE-AC05-00OR22725 



\section{CONTENTS}

LIST OF FIGURES

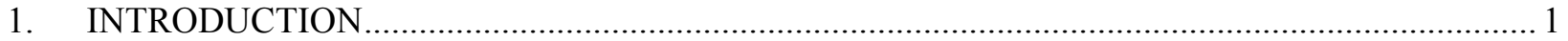

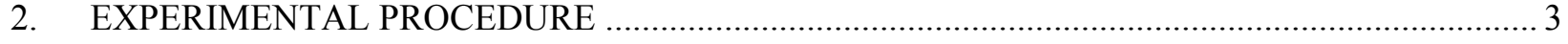

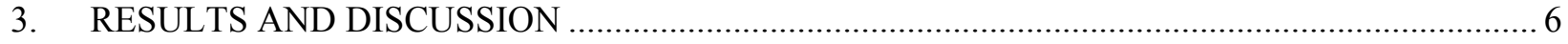

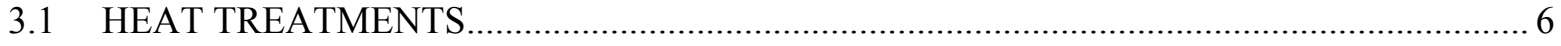

3.2 CAVITATION-EROSION TESTING IN MERCURY ….................................................. 9

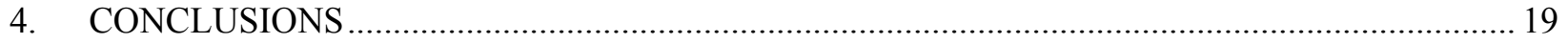

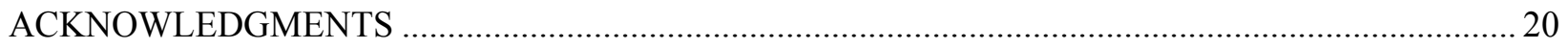

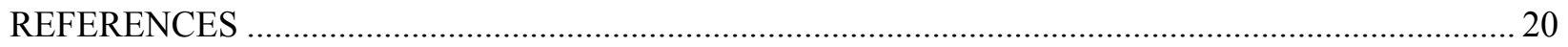





\section{LIST OF FIGURES}

Figure $\quad$ Page

1. Containment device used to heat treat specimens prior to sonication ..............................................

2. Schematic time-temperature chromium carbide precipitation diagram for austenitic stainless steel

3. Weight loss of selected specimens as a function of sonication time in mercury at $25^{\circ} \mathrm{C} \ldots \ldots \ldots \ldots \ldots \ldots . . . .10$

4. Average depth among six largest pits observed on the test surface following sonication for $6 \mathrm{~h}$ in mercury at $25^{\circ} \mathrm{C}$....

5. Diamond Pyramid Hardness profiles for heat treated specimens compared to an as-received carburized specimen

6. Scanning electron microscopy images of 316LN stainless steel following sonication in mercury at $25^{\circ} \mathrm{C}$ for $6 \mathrm{~h}$ representing the specimen carburized and heat treated $30 \mathrm{~min}$ at $650^{\circ} \mathrm{C}$

7. Scanning electron microscopy images of $316 \mathrm{LN}$ stainless steel following sonication in mercury at $25^{\circ} \mathrm{C}$ for $6 \mathrm{~h}$

8. Cross-section metallography of the near surface region of the carburized specimen heat treated $30 \mathrm{~min}$ at $650^{\circ} \mathrm{C}$ prior to testing ....

9. Cross-section metallography (etched with glyceregia) of the near surface region of the carburized specimen heat treated $60 \mathrm{~min}$ at $650^{\circ} \mathrm{C}$ prior to testing....

10. Cross-section metallography (etched with oxalic acid) of the near surface region of the carburized specimen heat treated $60 \mathrm{~min}$ at $650^{\circ} \mathrm{C}$ prior to testing.

\section{LIST OF TABLES}

Table

1. Composition (wt \%) of type 316LN stainless steel used as a substrate alloy in this investigation ........ 3

2. Time at temperature treatments used to evaluate sensitivity of the carburized material to thermal treatments

3. Specimen weight loss (mg) following $6 \mathrm{~h}$ of sonication in mercury at $25^{\circ} \mathrm{C}$ for each carburized specimen as a function of heat treatment prior to testing.

4. Range of pit/crater depth $(\mu \mathrm{m})$ among six largest observed on each specimen surface following $6 \mathrm{~h}$ of sonication in mercury at $25^{\circ} \mathrm{C}$ for each carburized specimen as a function of heat treatment prior to testing. 



\begin{abstract}
The cavitation-erosion resistance of carburized 316LN stainless steel was significantly degraded, but not eliminated, by heat treatment in the temperature range $500-800^{\circ} \mathrm{C}$. The heat treatments caused rejection of some carbon from the carburized layer into an amorphous film that formed on each specimen surface. Further, the heat treatments encouraged carbide precipitation and reduced hardness within the carburized layer, but the overall change did not reduce surface hardness fully to the level of untreated material. Heat treatments as short as $10 \mathrm{~min}$ at $650^{\circ} \mathrm{C}$ substantially reduced cavitation-erosion resistance in mercury, while heat treatments at 500 and $800^{\circ} \mathrm{C}$ were found to be somewhat less detrimental. Overall, the results suggest that modest thermal excursions - perhaps the result of a weld made at some distance to the carburized material or a brief stress relief treatment - will not render the hardened layer completely ineffective but should be avoided to the greatest extent possible.
\end{abstract}





\section{INTRODUCTION}

The Spallation Neutron Source (SNS) generates neutrons via interaction of a pulsed $(60 \mathrm{~Hz})$ proton beam $(1.0 \mathrm{GeV})$ with a liquid mercury target. During each pulse $(<1 \mu \mathrm{s})$, the local heating rate of the mercury is very high (order of $10^{7}{ }^{\circ} \mathrm{C} / \mathrm{s}$ ) thus giving rise to a thermal shock-induced compression wave within the mercury. When the compression wave reaches a target container surface, it is reflected back with a change of phase thus exposing the liquid mercury to negative pressure transients. These negative pressure transients are expected to be sufficient to generate cavitation voids [1-3] within the nominally pure mercury. When these voids collapse, some of the energy is released as a high-velocity jet of liquid capable of causing localized cavitation-erosion damage of the nearby surfaces.

Type 316/316LN stainless steel was selected as the container material for the mercury target in the SNS due to a favorable combination of well-characterized behavior in the neutron radiation environment and excellent general compatibility with mercury over the range of exposure conditions. However, annealed 316/316LN stainless steel has been shown to be quite susceptible to pitting and erosion damage in mercury when tested under cavitation conditions produced by a split Hopkinson pressure bar apparatus [4] or a drop-test variant [5], in-beam exposures [6-9], and a vibratory horn [10-13].

Over the past few years, various surface treatments for 316/316LN stainless steel have been evaluated in an effort to improve cavitation resistance in mercury. The most successful treatment to date, as evaluated by a vibratory horn technique using weight loss and pit depth to assess resistance, has been found to be a low temperature gas carburizing treatment. In this treatment, several weight percent carbon is diffused into the substrate stainless steel to a depth of 30-35 $\mu \mathrm{m}$. Because the carburizing is accomplished at a temperature well below that associated with precipitation of chromium carbides (which occurs most rapidly at $550-750^{\circ} \mathrm{C}$ for many stainless steel alloys [14]), the added carbon-well in excess of the amount soluble in austenite-is present as a supersaturated solid solution at room temperature, resulting in a significantly hardened surface (due to lattice strain) that simultaneously retains substantial toughness. Further, because the hardened surface results from a carbon diffusion gradient into the substrate, there is no distinct interface at which properties change in step-function fashion. Thus, there is no discreet initiation point for surface layer failure via loss of adhesion or cracking/spalling, as is often observed for surface coatings that do not penetrate and/or intimately bond with the substrate $[15,16]$.

Because the carbon present in the carburized surface layers is present in amounts significantly above the solubility limit for austenitic stainless steel, reheating of a treated stainless steel into a temperature regime 
capable of changing the carbon distribution/structure in the surface layer (such as might result from the thermal cycle associated with a nearby weld or from a stress relief heat treatment) could cause extensive chromium carbide formation in the carburized region. The purpose of this brief investigation is to assess potential degradation of the hardening and cavitation-erosion resistance of the carburized layer as a result of thermal treatments. 


\section{EXPERIMENTAL PROCEDURE}

The composition of the mill-annealed type 316LN stainless steel used in this investigation to make vibratory horn test specimens was identical to that used for previous cavitation-erosion experiments for the SNS in this laboratory and is reported in Table 1. As in previous sample fabrication, care was taken to cut specimens from the original plate such that the test specimen surface was parallel to the rolling direction to limit the number of inclusion stringers intersecting the specimen surface-relatively few in any case - and potentially giving rise to atypical carburizing results or cavitation response.

After fabrication, specimens received the standard carburizing treatment at the vendor's facility, resulting in specimens with a
Table 1. Composition (wt \%) of type 316LN stainless steel used as a substrate alloy in this investigation

Values taken from certified mill report.

\begin{tabular}{cc}
\hline Element & 316LN (wrought) \\
\hline $\mathrm{C}$ & 0.009 \\
$\mathrm{~N}$ & 0.11 \\
$\mathrm{Cr}$ & 16.31 \\
$\mathrm{Ni}$ & 10.2 \\
$\mathrm{Mo}$ & 2.07 \\
$\mathrm{Mn}$ & 1.75 \\
$\mathrm{Cu}$ & 0.23 \\
$\mathrm{Co}$ & 0.16 \\
$\mathrm{P}$ & 0.029 \\
$\mathrm{Si}$ & 0.39 \\
$\mathrm{~S}$ & 0.002 \\
$\mathrm{Fe}$ & Balance \\
\hline
\end{tabular}

uniform carburized depth of about $33 \mu \mathrm{m}$ on average and a hardness profile similar to that reported previously [17] for 316L stainless steel receiving this treatment. Following carburizing, the specimens were sealed in quartz tubes under high purity argon for heat treatment (Fig. 1). Argon was used to protect the specimens from oxidation rather than a vacuum within the quartz tube to speed heat transfer during furnace treatments. Because the quartz tubes partially insulate the specimen from the furnace heat and because the heat treatments were to be relatively brief (as short as $10 \mathrm{~min}$ at temperature), it was deemed necessary to creatively thermocouple the specimen to determine as precisely as possible the time required for the specimen to come to the desired treatment temperature. The method selected is shown in Fig. 1; the quartz enclosure was penetrated by a $0.32 \mathrm{~cm}$ OD quartz tube - open at one end and sealed with a flat bottom at the other end - that was inserted about $3 \mathrm{~cm}$ into the $8 \mathrm{~cm}$ long by $2 \mathrm{~cm}$ diameter cylindrical quartz container. A type-K thermocouple was inserted into the open end of the small tube and held in place against the bottom of the tube by crimping the thermocouple sheath appropriately. Within the bulk quartz enclosure, the test surface of the specimen was held against the flat-bottomed thermocouple tube via a wad of quartz wool. By nesting the thermocouple within the container and against the specimen surface in this fashion, it was anticipated that a faithful rendering of the specimen temperature within the insulating container could be estimated. 


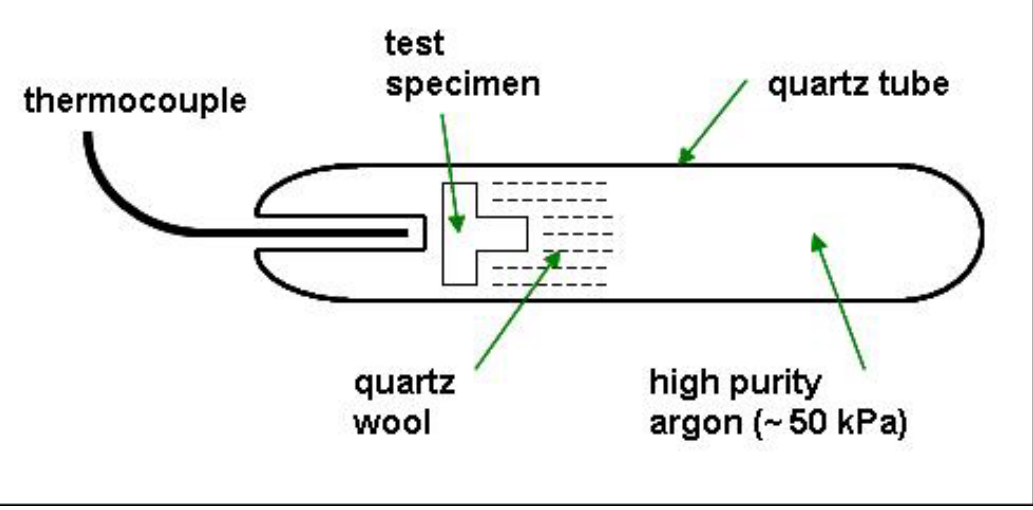

Fig. 1. Containment device used to heat treat specimens prior to sonication.

To accomplish the desired heat treatments, a box furnace was first equilibrated at the desired temperature, and then a specimen tube was positioned directly beneath the control thermocouple within the furnace. With the thermocouple nested in the quartz tube, the specimen temperature was observed to increase rapidly. Specimens were typically within $10^{\circ} \mathrm{C}$ of the desired temperature in 4-5 min furnace time, and the heat treatment "clock" was started at that point. At the conclusion of the heat treatment time, the specimen was quenched rapidly by immediately placing the quartz tube into a bucket of water where it was smashed on one end to allow instant contact with cooling water.

The specific heat treatments utilized in this investigation are summarized in Table 2. Mill-annealed (as-received) 316L stainless steel—with and without the carburizing process but no subsequent heat treatment — was also included in the cavitation test matrix via previous evaluation $[13,15]$. It should be noted that these particular heat treatments were

Table 2. Time-at-temperature treatments used to evaluate sensitivity of the carburized material to thermal treatments

\begin{tabular}{cc}
\hline $\begin{array}{c}\text { Temperature } \\
\left({ }^{\circ} \mathbf{C}\right)\end{array}$ & $\begin{array}{c}\text { Time } \\
(\mathbf{m i n})\end{array}$ \\
\hline 500 & 30,60 \\
650 & $10,30,60,120$ \\
800 & 30,60 \\
\hline
\end{tabular}
not selected to simulate a specific weld thermal cycle or any anticipated treatment; rather, they were selected simply as representative of a range of potentially deleterious possibilities useful to evaluate sensitivity to thermal treatment. The choice of specific conditions is discussed in the next section.

Cavitation-erosion tests were performed using a titanium vibratory horn and the general test methodology described in ASTM G-32 [18]. Each test specimen had a surface area of $180 \mathrm{~mm}^{2}$ exposed to cavitation conditions and was attached to the vibratory horn tip via a threaded shank (other specimen details are reported in [13]). In each test, the horn tip oscillated at a fixed frequency of $20 \mathrm{kHz}$ with a peak-to-peak vibrational amplitude of $25 \mu \mathrm{m}$. The test specimen surface on the horn tip was immersed about $2 \mathrm{~mm}$ 
into the pure mercury pool in the center of a jacketed stainless steel container (about $10 \mathrm{~cm}$ diameter, $11 \mathrm{~cm}$ depth of mercury). A water/glycol mixture was circulated through the jacket to maintain a constant temperature of $25-26^{\circ} \mathrm{C}$ during sonication. Periodically, cheesecloth was used to skim the mercury surface to remove floating oxide and/or test debris.

Following sonication, the test specimens were ultrasonically cleaned sequentially in (1) a commercial aqueous solution containing dissolved sulfur species to chemically bind residual mercury, (2) distilled water, and (3) acetone, followed by forced air drying after each step. Specimens were then weighed and subsequently examined with an optical microscope to assess the cavitation-erosion surface profile and any pitting damage. In both cases, the calibrated fine focus feature of the microscope stage was used to estimate the distance between high and low points in a given field of view to evaluate relative surface profile and pit depth. Periodically, specimens were also examined with the scanning electron microscope (SEM) and eventually (at the end of the total intended test duration) sectioned for metallographic evaluation of the cross section. 


\section{RESULTS AND DISCUSSION}

\subsection{HEAT TREATMENTS}

Most austenitic stainless steels are placed into service in the solution treated condition. Solution treatment typically involves soaking at elevated temperature (generally about $1050^{\circ} \mathrm{C}$ for types 304 and 316 austenitic stainless steels) to homogenize the alloy composition to the greatest extent possible, followed by rapid cooling (generally quenched into water or rapidly flowing gas) to maintain the homogenized structure at ambient temperature. For austenitic stainless steels like types 304 and 316, the primary goal of solution treatment is to place all the carbon in the alloy ( $0.08 \mathrm{wt} \%$ or less) into solid solution to maximize corrosion resistance. However, because the solubility of carbon in austenite decreases rapidly with decreasing temperature (depending on overall composition and processing variables, the solubility of carbon in austenitic stainless steels is about $0.05 \mathrm{wt} \%$ at $1000^{\circ} \mathrm{C}$, less than $0.01 \mathrm{wt} \%$ at $900^{\circ} \mathrm{C}$, and vanishingly small at temperatures below $600-700^{\circ} \mathrm{C}$ [19]), solution treatment generally results in a material that is supersaturated in carbon at room temperature. Subsequent elevated temperature treatments - e.g., welding thermal cycles, stress relief treatments - may relieve the supersaturation by encouraging chromium carbide precipitation within the alloy. When this occurs, the predominant carbide formed, at least for nominal carbon content alloys, is of the type $\mathrm{M}_{23} \mathrm{C}_{6}$, where $\mathrm{M}$ is primarily chromium but small amounts of iron or other metallic elements are also possible. The substantial amount of chromium required to form these carbides depletes the alloy of chromium adjacent to the carbides (typically at grain boundaries for nominal carbon content alloys), often to a degree sufficient to compromise corrosion resistance in many environments. When this occurs, the stainless steel is typically referred to as "sensitized."

The changes expected within the carburized layer as a result of thermal treatments are difficult to predict because so many factors are involved, and selecting a heat treatment potentially detrimental to retention of cavitation-erosion resistance is not straightforward. A starting point for the thought process, however, is to consider the sensitizing process for a stainless steel. The tendency for carbon supersaturation to be relieved via precipitation of chromium carbides in an austenitic stainless steel of nominal carbon content is proportional to both the degree of supersaturation (the amount of carbon present compared to the

solubility limit) and the temperature to which the alloy is exposed (which influences the diffusion rate of chromium in carbide formation). At relatively low temperatures, the degree of supersaturation is maximized - thus, a higher thermodynamic driving force for precipitation — but atomic mobility is restricted due to limited diffusion, and so carbide precipitation is retarded. Conversely, at relatively elevated temperatures, atomic mobility is high, but the degree of supersaturation driving precipitation is 
drastically reduced so, again, carbide precipitation is relatively limited. At intermediate temperatures, however, the combination of adequate atomic mobility and considerable supersaturation tends to maximize the speed and extent of carbide precipitation. Thus, the sensitization of austenitic stainless steel can often be described by a "c-shaped" curve in a time-temperature (isothermal) plot, as suggested by the schematic diagram in Fig. 2.

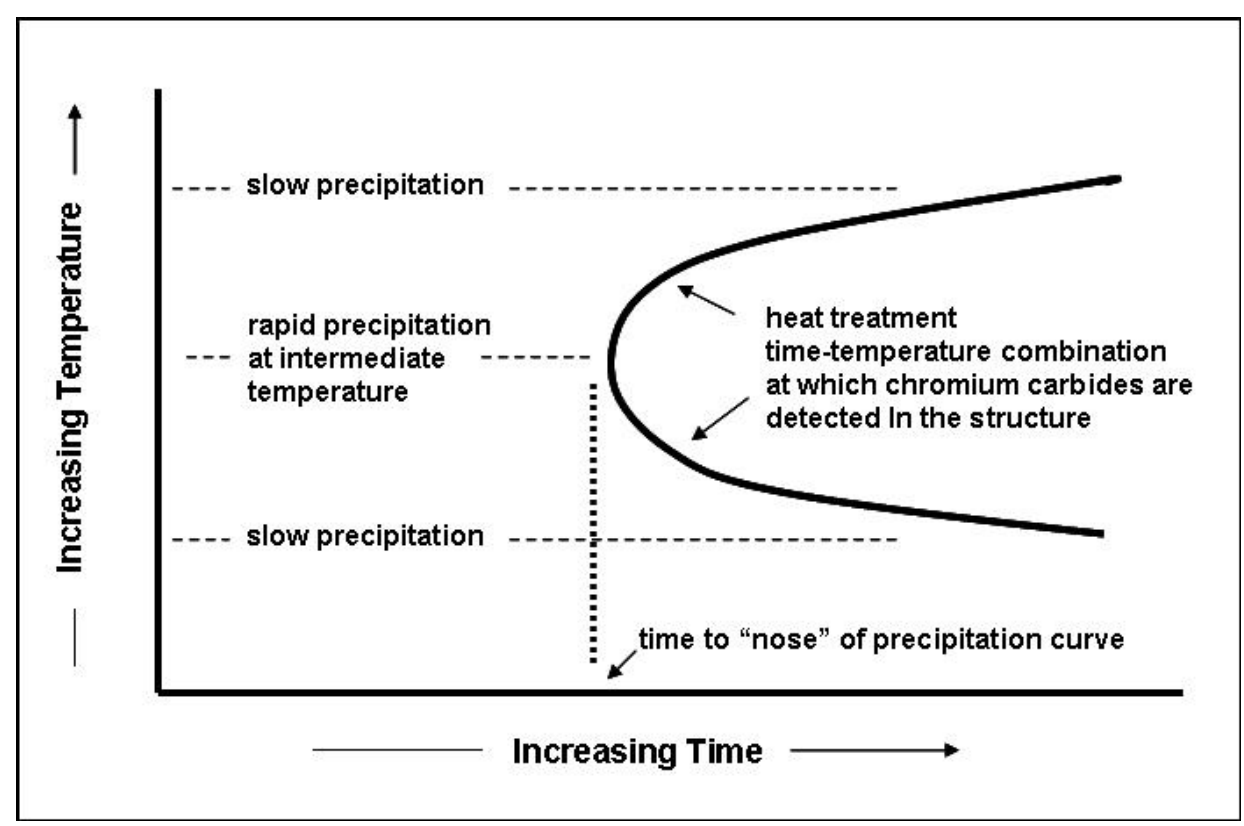

Fig. 2. Schematic time-temperature chromium carbide precipitation diagram for austenitic stainless steel.

The time-temperature details of a plot similar to Fig. 2 for a specific alloy are of course dependent on the alloy composition, the thermomechanical treatment, and the sensitivity of the technique(s) used to identify carbide precipitation, but for a nominal austenitic stainless steel, the "nose" of the precipitation (or corrosion damage) curve tends to be located in the temperature range $600-700^{\circ} \mathrm{C}$. The time required for substantial carbide precipitation to occur is typically $30-60 \mathrm{~min}$ at $600-700^{\circ} \mathrm{C}$ for relatively high carbon alloys (much longer for low carbon alloys), with precipitation becoming very sluggish (requiring hours or even days) as heat treatment temperatures decrease to about $500^{\circ} \mathrm{C}$ or increase to about $800^{\circ} \mathrm{C}$ $[10,15]$. These nominal times/temperatures to cause carbide precipitation in $316 \mathrm{LN}$ could be distorted substantially noting that the carburized layer in these specimens contains perhaps $4-5 \mathrm{wt} \%$ carbon [15] in solid solution - that is, 2-3 orders of magnitude more carbon than a traditional austenitic stainless steel following solution treatment. This extreme supersaturation (manifested in lattice strain) is the primary source of hardening resulting from the carburizing process, but very little is known about how quickly that level of supersaturation might result in carbide precipitates as a function of various heat treatment conditions, or about how sensitive the cavitation-erosion resistance of the treated surface might be to 
various degrees of precipitation. Examination of the latter factor is ultimately the purpose of this investigation, and the specific heat treatments incorporated into this evaluation were selected simply to represent the nominal range of sensitizing temperatures for a typical stainless steel; that is, a range incorporating temperatures in which chromium carbides readily precipitate from a solution treated austenitic structure $\left(650^{\circ} \mathrm{C}\right)$ as well as temperatures at which precipitation might be more sluggish (500 and $800^{\circ} \mathrm{C}$ ). Because of the extreme level of carbon supersaturation in the treated layers - which suggests that the driving force associated with degree of supersaturation is very large in all cases - relatively short times (10-120 $\mathrm{min})$ were chosen for the heat treatment durations in this investigation.

Following heat treatment and water quenching, the carburized specimens exhibited a relatively uniform dark charcoal gray/black film. Initially, it was thought that the film was a typical oxide formed as a result of exposure to contaminated argon during the heat treatment process and/or perhaps brief exposure to water during the quenching procedure. In an attempt to remove the oxide prior to cavitation testing, the first several heat treated specimens with this discoloration were exposed to a brief pickling treatment ( 1-2 min immersion in 10\% nitric acid with $2 \%$ hydrofluoric acid at room temperature [20]). However, the pickling treatment proved very ineffective for removal of the discoloration/film, suggesting it was not a standard oxide of chromium and iron (which is very readily dissolved by this pickling solution). Subsequently, surface analysis using X-ray photoelectron spectroscopy revealed that the film on the specimens was almost exclusively (80-85\%) amorphous carbon—not a carbide or graphite - mixed with minor amounts of iron and chromium oxides (15-20\%). The amount of oxide perhaps increased slowly as analysis position within the film approached the substrate, but the rate of change was small. The total film thickness was not analytically assessed following heat treatment or pickling, but it was observed in limited optical microscopy to be highly variable among specimens and across any specimen surface (15-20 $\mu \mathrm{m}$ is perhaps a representative average value).

Ultimately, pickling was discontinued and the residual film was allowed to remain on the specimen surfaces for cavitation testing. In some cases, the film had been attacked by the pickling solution prior to testing; for other specimens, no pickling treatment was imposed. It is not clear what influence this disparity may have had on the cavitation test results, but no additional specimens were available to extend the investigation. Prior to sonication, light microscopy evaluation revealed shallow etching on the pickled test surfaces. Grain boundaries associated with the substrate were faintly evident (as might be expected for acid attack of a sensitized stainless steel), and in some locations, triple points revealed evidence of grain dropping. The grain faces of the pickled specimens, however, remained significantly discolored and revealed no particular roughening or attack. The pickling process also resulted in a significant weight loss, on the order of $50 \mathrm{mg}$ for each specimen. The weight loss is significantly more than resulted from 
the sonication process for most specimens, but recall that the entire specimen was pickled, yielding general corrosion and light grain dropping from an area more than three times larger than the test surface exposed to cavitation. The specimens that were not pickled revealed only indistinct surface variations and modest color variations associated with the thin film. The cavitation-erosion process on the specimen surfaces was only marginally effective in removing discoloration. Very little dark charcoal/black coloration remained after the initial hour of sonication, but remnants of discoloration remained on many specimens even after $6 \mathrm{~h}$ of sonication.

Due to these uncertainties, the results and discussion that follow focus primarily on the specimens that received the brief pickling treatment. Data for the other specimens (the specimen representing the longest heat treatment time at each temperature was not pickled) are included where appropriate, but absolute comparison of results may be complicated somewhat by the difference in surface cleaning (pickling or not). However, the trends in the data are sufficiently uniform - independent of cleaning procedure, and involving effects much deeper into the material than the surface film thickness - that the results appear meaningful.

\subsection{CAVITATION-EROSION TESTING IN MERCURY}

The weight loss of selected specimens as a function of sonication time is shown in Fig. 3. Like many other 316LN specimens evaluated in this program (carburized specimens, as well as $316 \mathrm{LN}$ receiving no surface treatment), the weight loss was essentially linear after the initial exposure period. It is apparent that heat treatment at $650^{\circ} \mathrm{C}$ significantly degraded the cavitation-erosion resistance of the carburized surface, but even specimens treated at $650^{\circ} \mathrm{C}$ exhibited superior resistance (near a factor of two based on weight loss) when compared to the untreated material (annealed, no carburizing). Note also that heat treatment at $800^{\circ} \mathrm{C}$ and, particularly, heat treatment at $500^{\circ} \mathrm{C}$ had relatively little effect on weight loss results in the ultrasonic horn test. Table 3 further summarizes the weight loss for all specimens as a function of heat treatment condition following the $6 \mathrm{~h}$ sonication. Table 4 provides the corresponding data for the range of pit depths observed on each specimen as a function of heat treatment condition following $6 \mathrm{~h}$ of sonication. 


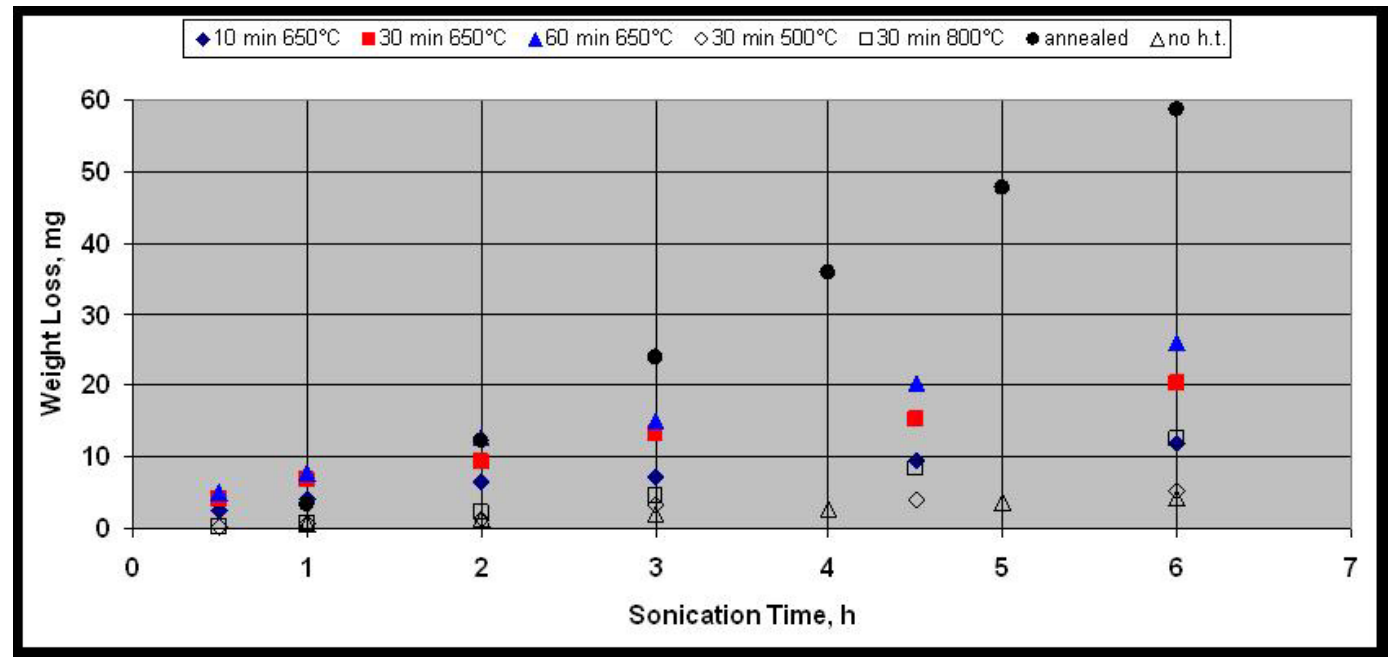

Fig. 3. Weight loss of selected specimens as a function of sonication time in mercury at $25^{\circ} \mathrm{C}$. In the legend, the time-temperature information refers to the heat treatment received by a carburized specimen prior to testing. For comparison, data for a carburized $316 \mathrm{LN}$ specimen that was not subsequently heat treated ( $\Delta$ no h.t.) and an annealed $316 \mathrm{LN}$ specimen that was not carburized (• annealed) are also included. Some of the specimens evaluated in this investigation were omitted because the data points were indistinguishable from others in the graph.

Table 3. Specimen weight loss ( $\mathrm{mg}$ ) following $6 \mathrm{~h}$ of sonication in mercury at $25^{\circ} \mathrm{C}$ for each carburized specimen as a function of heat treatment prior to testing ${ }^{a}$

\begin{tabular}{ccccc}
\hline \multirow{2}{*}{$\begin{array}{c}\text { Heat treatment } \\
\text { temperature }\left({ }^{\circ} \mathbf{C}\right)\end{array}$} & \multicolumn{4}{c}{ Mass loss $(\mathbf{m g})$ for indicated exposure conditions } \\
\cline { 2 - 5 } & $\mathbf{1 0} \mathbf{~ m i n}$ & $\mathbf{3 0} \mathbf{~ m i n}$ & $\mathbf{6 0 ~} \mathbf{~ m i n}$ & $\mathbf{1 2 0} \mathbf{~ m i n}$ \\
\hline 800 & & 12.6 & 8.2 & \\
650 & 11.8 & 20.3 & 26.0 & 11.3 \\
500 & & 5.2 & 7.6 & \\
\hline
\end{tabular}

${ }^{a}$ For comparison, the equivalent weight loss value for a carburized specimen with no subsequent heat treatment was $4.4 \mathrm{mg}$, and for a solution treated $316 \mathrm{LN}$ specimen (no Kolsterising ${ }^{\mathbb{R}}$ ), the weight loss was $58.7 \mathrm{mg}$.

Table 4. Range of pit/crater depth $(\mu \mathrm{m})$ among six largest observed on each specimen surface following $6 \mathrm{~h}$ of sonication in mercury at $25^{\circ} \mathrm{C}$ for each carburized specimen as a function of heat treatment prior to testing ${ }^{a}$

\begin{tabular}{ccccc}
\hline \multirow{2}{*}{$\begin{array}{c}\text { Heat treatment } \\
\text { temperature }\left({ }^{\circ} \mathbf{C}\right)\end{array}$} & \multicolumn{4}{c}{ Pit depth $(\boldsymbol{\mu m})$ for indicated exposure conditions } \\
\cline { 2 - 5 } & $\mathbf{1 0} \mathbf{~ m i n}$ & $\mathbf{3 0}$ min & $\mathbf{6 0}$ min & $\mathbf{1 2 0} \mathbf{~ m i n}$ \\
\hline 800 & & $44-96$ & $29-97$ \\
650 & $46-69$ & $81-106$ & $95-108$ & $35-88$ \\
500 & & None & $47-140$ & \\
\hline
\end{tabular}

${ }^{a}$ For comparison, no pits at all were observed on carburized specimens that received no subsequent heat treatment, while pits $>200 \mu \mathrm{m}$ deep were observed on solution treated $316 \mathrm{LN}$ specimens (no carburizing). 
Note that the weight loss results in Table 3 indicate that increasing treatment time at a given temperature often resulted in a further degradation of cavitation-erosion resistance in mercury, although there were a couple of exceptions. In particular, note the pattern in the results for $650^{\circ} \mathrm{C}$ : the longest heat treatment time $(120 \mathrm{~min})$ actually resulted in the lowest weight loss following $6 \mathrm{~h}$ sonication. Since this particular specimen was not pickled prior to testing, an influence of surface condition cannot be discounted, but it seems likely that there could be contributions to this behavior that include diffusion of supersaturated carbon (to decrease the subsurface gradient) as well as reorganization of the carbides (for example, in terms of size, distribution, and coherency with the lattice to change the residual stress state). These changes, which could enhance toughness within the carburized layer and thus improve resistance to cavitation-erosion in mercury, might be expected at all the heat treatment temperatures evaluated, but they might also be expected to occur fastest at the highest temperatures, which was observed in the data (see Table 3). As a matter of speculation, a potential analogy for this behavior related to corrosion resistance is the "healing" that can be observed within a sensitized stainless steel. Immediately following chromium carbide formation, the surrounding matrix is relatively chromium depleted, thus rendering the material susceptible to localized corrosion, but extended heat treatment time at the sensitizing temperature allows diffusion of chromium from the bulk alloy to largely replenish the chromium-depleted regions, which can reestablish localized corrosion resistance to the alloy. Although it seems likely that the heat treatment times may be too short for an analogous phenomenon, perhaps the extended time at temperature on this heat treated specimen permits sufficient reordering of the carbon and carbides to partially restore cavitation resistance.

Note that the information contained in Table 4 complements that in Table 3, but these tables do not convey the same information. Table 3 reports total weight change resulting from the sonication process, and to compare these values among the different treatments, one must assume a relatively uniform wastage. However, in a general sense, uniform wastage of SNS target containment materials is not a substantial threat to long-term service life. Rather, a more significant threat is the localized formation of pits/craters, which for many specimen and surface treatment combinations may reach depths more than an order of magnitude greater than the general roughening observed in these tests. In any case, once the hardened layer is breached via uniform wastage or crater formation, there is little cavitation-erosion resistance in the underlying annealed base metal. Table 4 reveals that the range of depths observed for the half-dozen largest indications on each specimen generally followed weight loss trends - that is, higher weight loss roughly corresponds to deeper pits—but it should be recognized that neither the total number of pits (or the area of any given pit) nor the depth of uniform wastage is recorded in Table 3 . In 
particular, it should be noted that the pit depth data for the specimen heat treated $60 \mathrm{~min}$ at $500^{\circ} \mathrm{C}$ had one unusually deep pit that skews the result trend compared to weight change.

Although not absolutely true in every case, the first pits to form on the vibratory horn specimen surface tend to be the deepest as a function of exposure time because once the hardened layer is breached, erosion of the exposed base metal (very soft) is much more rapid than that of the remaining hardened layer. That trend was observed in these tests, and the depth of the largest pits could be followed as a function of sonication time. Representative results appear in Fig. 4. Here, the depth of the six deepest pits on selected specimens (all heat treated at $650^{\circ} \mathrm{C}$ ) was plotted as a function of sonication time and compared to the depth of general roughening of surfaces without an obvious pit/crater. The results indicate that the general surface roughness of the specimens heat treated at $650^{\circ} \mathrm{C}$ increased in depth at a rate similar to the increase in pit depth as a function of exposure time. This suggests that heat treatment at $650^{\circ} \mathrm{C}$ substantially degraded the protective qualities of the carburized layer and that sonication energy in the vibratory horn test is not particularly focused or intense at existing craters. For comparison, consider that the slope of the trend line for increase in general roughness with time is about $70 \%$ of that observed for annealed (but not carburized) $316 \mathrm{LN}$ specimens subjected to the same testing [15] and is a factor of about 20 greater than that observed for long-term sonication of carburized specimens with no heat treatment [21].

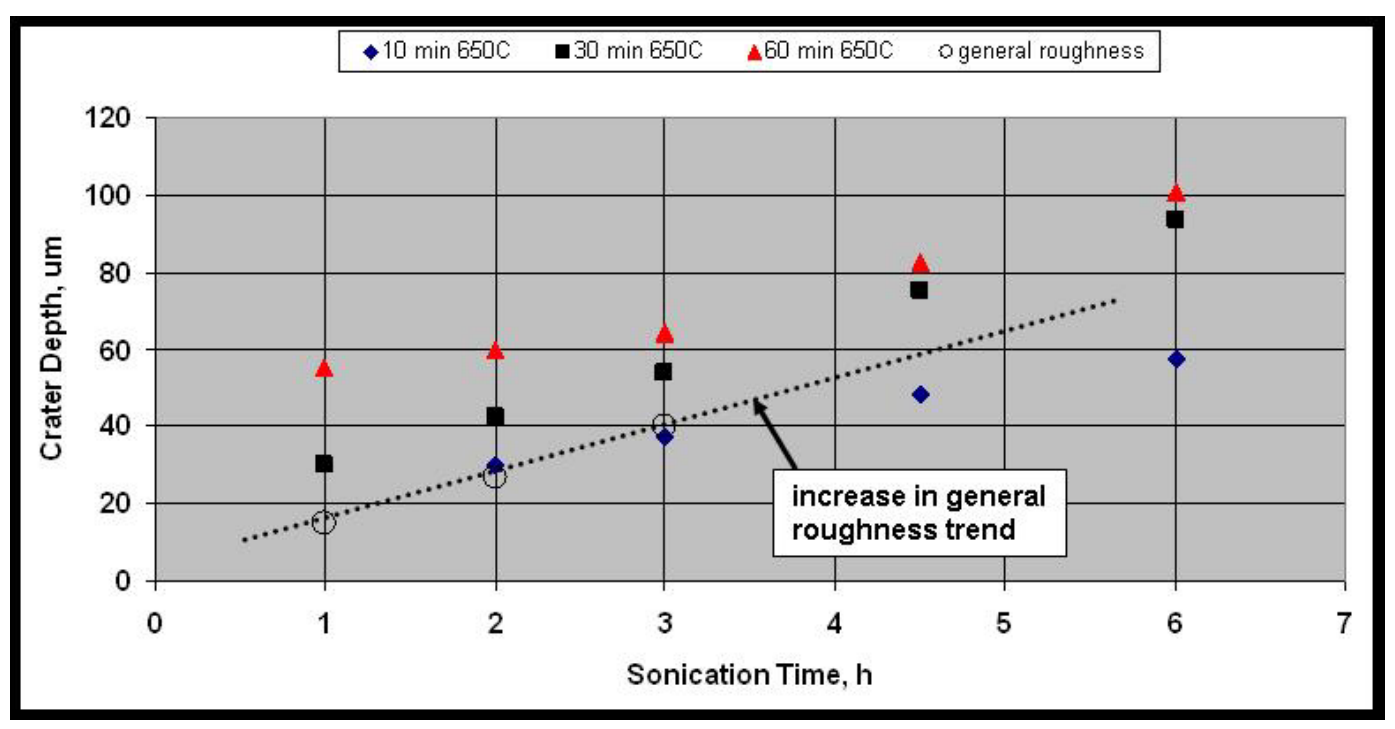

Fig. 4. Average depth among six largest pits observed on the test surface following sonication for $6 \mathbf{h}$ in mercury at $25^{\circ} \mathbf{C}$. In the legend, the time-temperature information refers to the heat treatment received by a carburized specimen prior to testing. Data for general roughness were collected from seven random but uniformly spaced locations across the surface that were not macroscopically pitted. 
Figure 5 provides microhardness data taken from cross sections of carburized specimens heat treated in a range of conditions, as well as carburized specimens with no heat treatment, that were prepared for metallography. The data reveal that heat treatment at all temperatures reduced the hardness associated with the carburized layer but that hardness remained at least slightly above the baseline condition (annealed, untreated 316LN at $200 \mathrm{DPH}$ ) in the treated layer. (For specimens evaluated here, it was difficult to get reproducible hardness values closer to the surface than about $10 \mu \mathrm{m}$ for heat treated specimens, perhaps due to the relative lack of hardness and distortion of the diamond indentation at this location.) These hardness results are only marginally consistent with the weight loss and pit depth data in that the specimen heat treated $30 \mathrm{~min}$ at $500^{\circ} \mathrm{C}$ exhibited among the highest residual hardness in the carburized layer, but the specimen heat treated $30 \mathrm{~min}$ at $800^{\circ} \mathrm{C}$ was comparatively low at many measurement points (yet it retained superior cavitation-erosion resistance compared to specimens heat treated at $650^{\circ} \mathrm{C}$ ). Clearly, surface hardness is not the only factor influencing cavitation resistance [13].

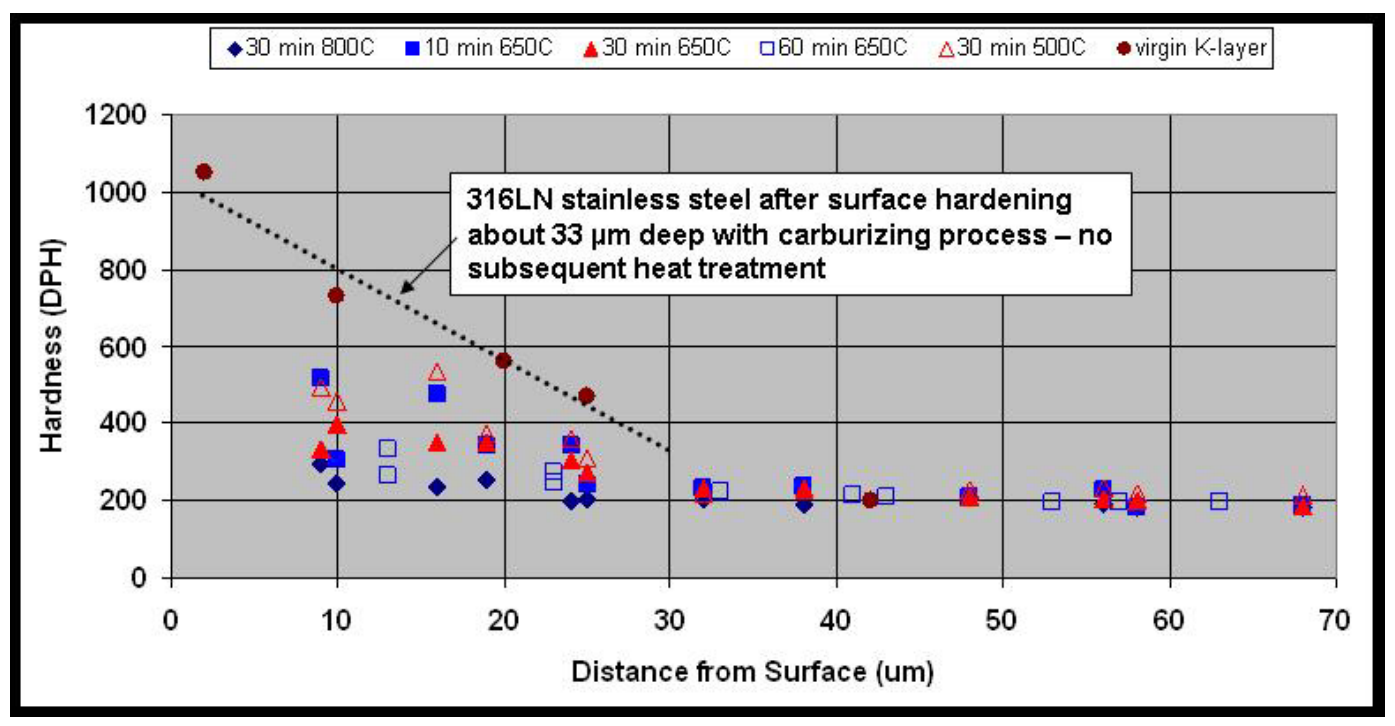

Fig. 5. Diamond Pyramid Hardness profiles for heat treated specimens compared to an asreceived carburized specimen. Hardness data were collected with a $50 \mathrm{~g}$ load. The nominal depth for some hardening associated with this carburizing process is $33 \mu \mathrm{m}$.

Following sonication and optical microscopy to examine surface roughening and pit depth, specimens were examined in the SEM to assess topography in more detail. Figure 6 is representative of the results for all specimens heat treated at $650^{\circ} \mathrm{C}$. The topmost photograph reveals the general surface features, which are dominated by relatively uniform craters spread randomly across the exposed surface. The number of craters per unit of surface area increased somewhat as the heat treatment time was extended from 10 to 30 to $60 \mathrm{~min}$ at $650^{\circ} \mathrm{C}$, and the average depth of the largest craters increased modestly as well (see Table 4). 


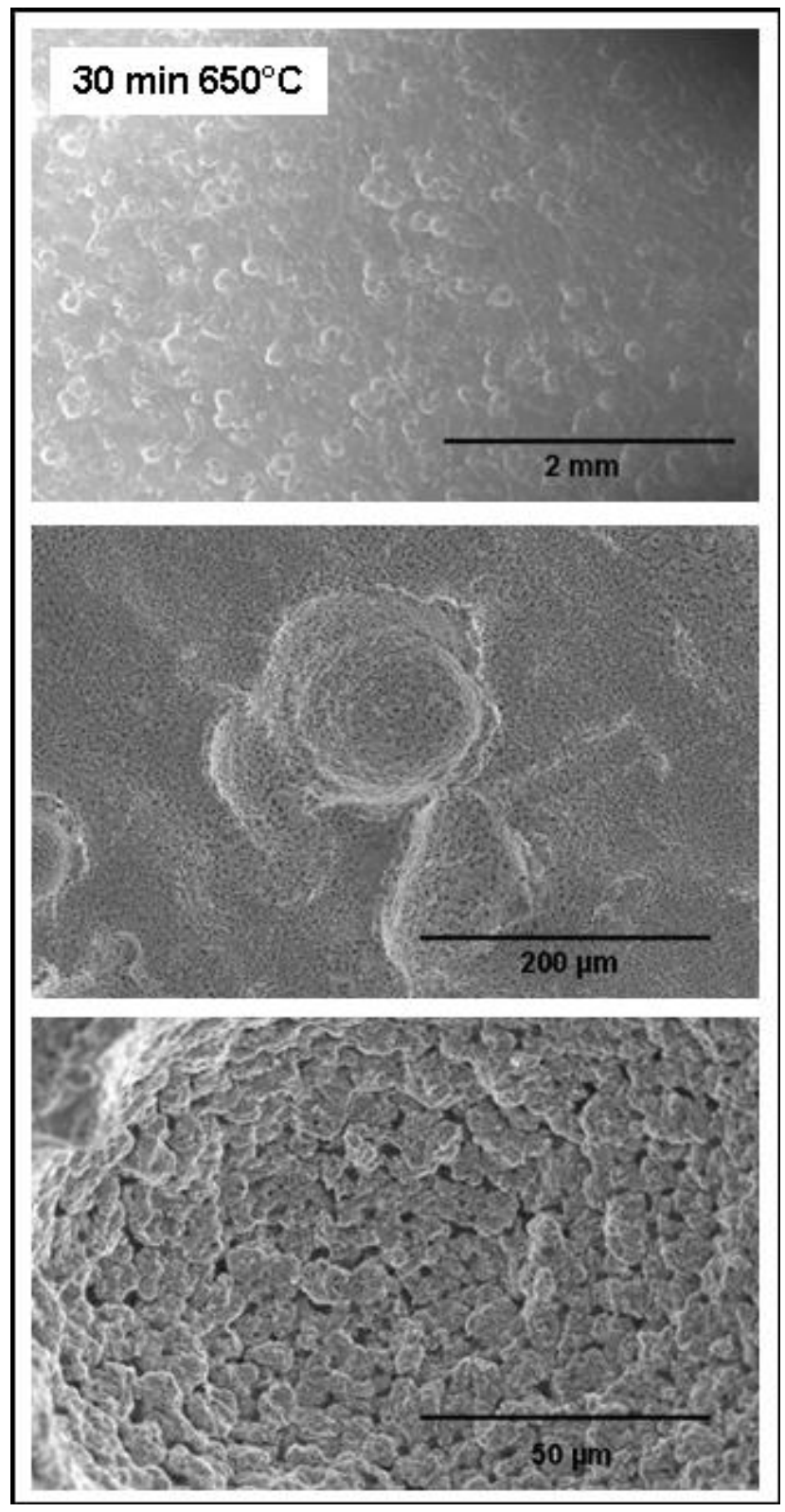

Fig. 6. Scanning electron microscopy images of 316LN stainless steel following sonication in mercury at $25^{\circ} \mathrm{C}$ for $6 \mathrm{~h}$ representing the specimen carburized and heat treated $30 \mathrm{~min}$ at $650^{\circ} \mathrm{C}$. Series of images of the same general area at increasing magnification from top to bottom.
The middle photograph in Fig. 6 shows a crater surrounded by a generally roughened surface, which indicates roughening of the bulk surface very similar in fine detail to the damage observed at the bottom of a crater (consistent with the discussion about the data in Fig. 4). The bottom photo represents the surface exposed at the floor of a pit/crater at relatively high magnification; the features here are identical to those observed for many other specimens of stainless steel examined in this program, suggesting that the general mechanism of cavitation-erosion remains consistent (i.e., microcracks initiate and coalesce under bombardment by shock waves to effect material loss on a small scale [13]) despite prior carburizing and heat treatment of the specimens examined herein.

Figure 7 shows representative SEM photographs of the test surface of specimens heat treated for $30 \mathrm{~min}$ at 500 and $800^{\circ} \mathrm{C}$ at the same series of magnifications shown in Fig. 6 for ease of comparison. Note that there are no pits/craters on the specimen heat treated at $500^{\circ} \mathrm{C}$ - only some modest "wrinkling" of the surface similar to that observed on carburized specimens (no heat treatment) following extended sonication [21]. The specimen heat treated at $800^{\circ} \mathrm{C}$ reveals an intermediate amount of roughening and pit formation compared to specimens heat treated at 500 and $650^{\circ} \mathrm{C}$. In all cases, the finest level of detail on the eroded/damaged surface is similar. 


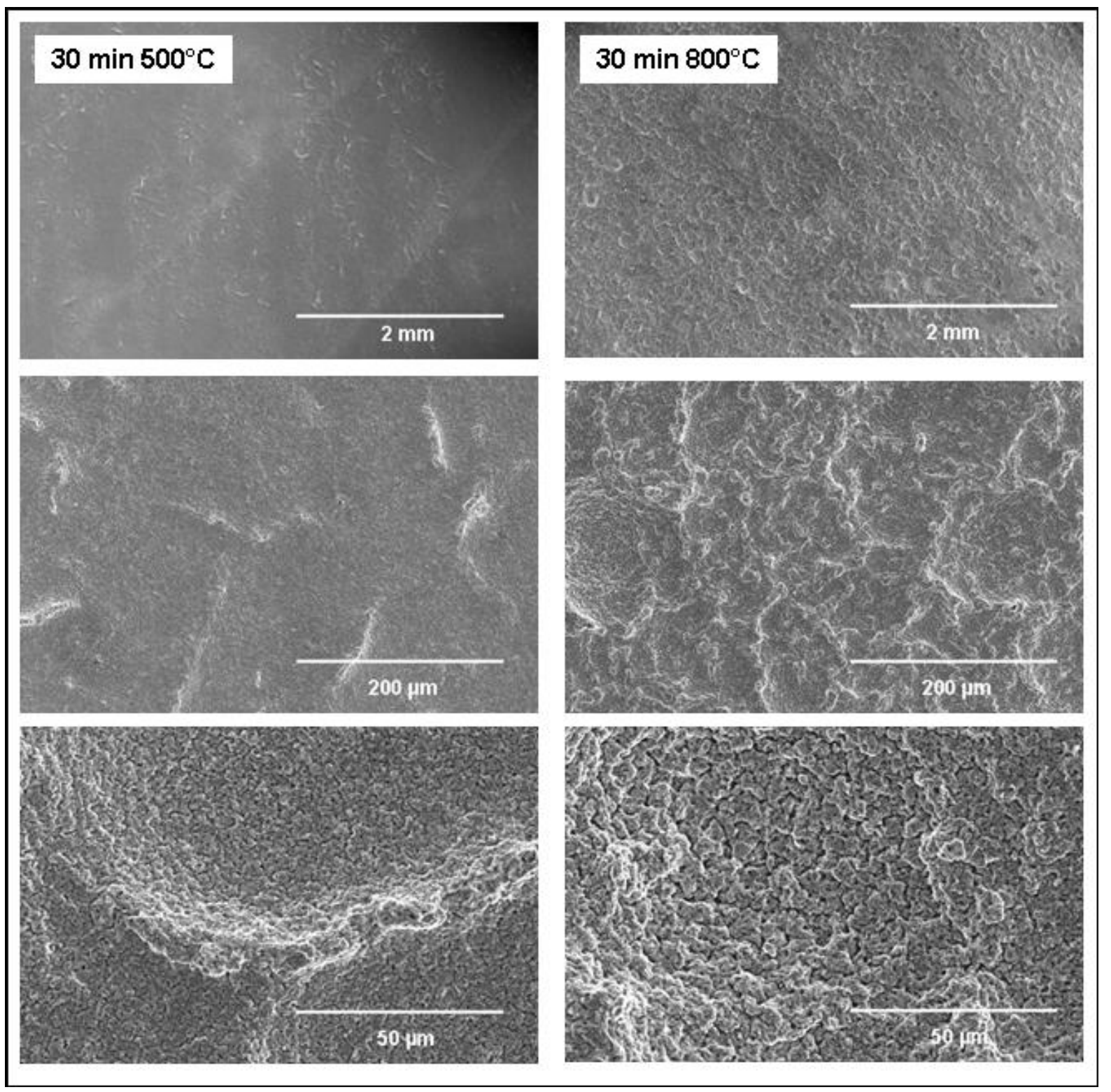

Fig. 7. Scanning electron microscopy images of $316 \mathrm{LN}$ stainless steel following sonication in mercury at $25^{\circ} \mathbf{C}$ for $6 \mathbf{~ h}$. Images in the left column represent $316 \mathrm{LN}$ that was carburized and heat treated $30 \mathrm{~min}$ at $500^{\circ} \mathrm{C}$, and images in the right column are equivalent views of materials heat treated $30 \mathrm{~min}$ at $800^{\circ} \mathrm{C}$. 


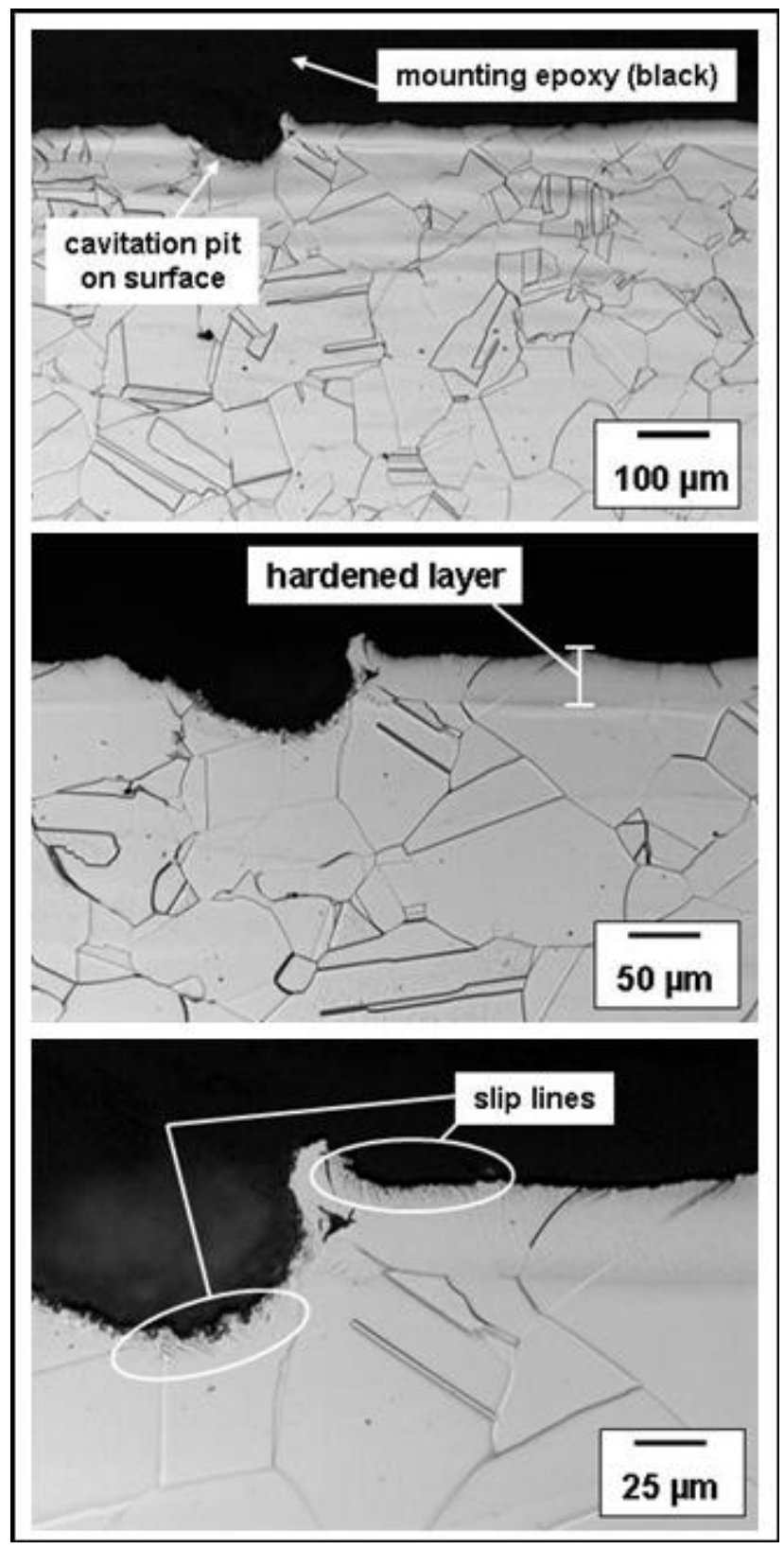

Fig. 8. Cross-section metallography of the near surface region of the carburized specimen heat treated $30 \mathrm{~min}$ at $650^{\circ} \mathrm{C}$ prior to testing. Etched with glyceregia.
At the completion of these tests, selected specimens were sectioned for metallographic analysis of the material structure and damage profiles. Figure 8 is representative of the results for the carburized specimen heat treated $30 \mathrm{~min}$ at $650^{\circ} \mathrm{C}$ prior to testing. The base metal structure is equiaxed austenite grains with little or no precipitate on the bulk grain boundaries. The hardened layer is about $35 \mu \mathrm{m}$ thick (its presence is indicated by a slight change in etching behavior near the surface) with a structure largely contiguous with that visible in the base material and little evidence of carbide precipitation. Note that the hardened layer has not been thinned substantially; it remains very close to $35 \mu \mathrm{m}$ thick even after a $6 \mathrm{~h}$ sonication, except in areas where it has been breached entirely at a pit location.

Note that the pit/crater visible in Fig. 8 does not appear hemispherical in this view; this is a common observation associated with vibratory horn tests in mercury and indicates sensitivity to a number of variables associated with proximity and angle to the nearby surface of collapsing cavitation voids as well as the energy associated with such a collapse. At the highest magnification, slip lines are visible on the bulk surface as well as at the bottom of the pit. The presence of slip lines is an indicator of the plastic deformation occurring on the surface as a result of the sonication process. As further evidence of the violence of the cavitation-erosion process, note the twisted/deformed "lip" of material at the crater surface where it intersects the bulk surface. This type of distortion has been observed previously on a variety of hardened surfaces $[21,22]$ and, similarly, the 
apparent interface between the hardened layer and the substrate does not reveal evidence of cracking or decohesion.

Figure 9 shows the cross section of a carburized specimen heat treated $60 \mathrm{~min}$ at $650^{\circ} \mathrm{C}$ prior to sonication. This is a somewhat longer heat treatment than for the specimen shown in Fig. 8 and, for equivalent etching, the structure reveals some modest differences. Primarily, note that the grain boundaries within the hardened layer now reveal some evidence of precipitation. In addition, the extreme surface (outermost $10 \mu \mathrm{m}$ or so) is heavily etched, indicating a dense precipitate at this location. The longer heat treatment time may have encouraged

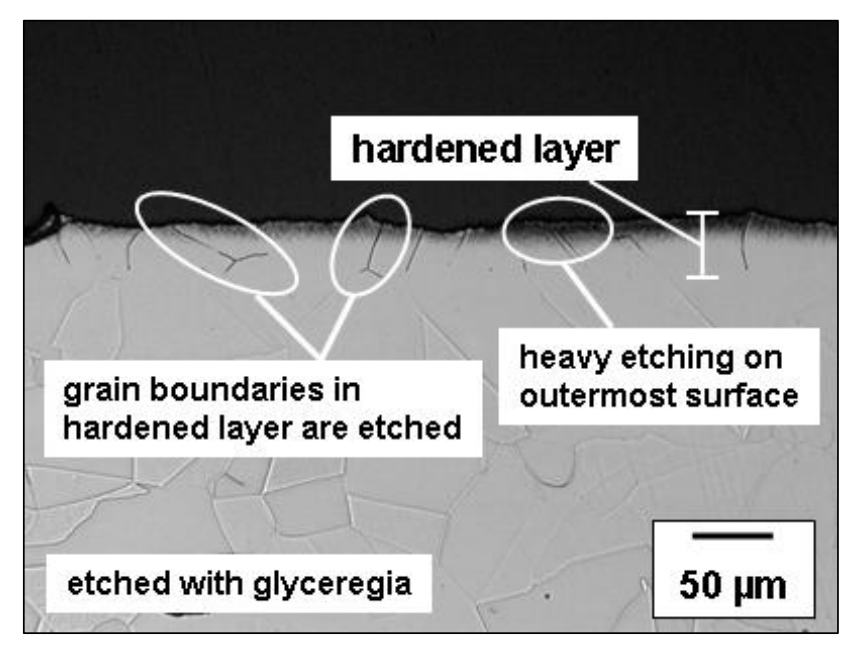

Fig. 9. Cross-section metallography (etched with glyceregia) of the near surface region of the carburized specimen heat treated $60 \mathrm{~min}$ at $650^{\circ} \mathrm{C}$ prior to testing. precipitation of carbides in the region of highest carbon content. This observation is also consistent with that of an extensive evaluation of the carburized region [17], which found iron carbides (possibly $\mathrm{Fe}_{5} \mathrm{C}_{2}$ ) irregularly concentrated in the outermost portion of the hardened region in the as-carburized condition.

Figure 10 is from the same specimen (different location) as that shown in Fig. 9, but it has been etched electrolytically with $10 \%$ oxalic acid. This etchant is very aggressive toward most carbide precipitates (particularly chromium carbides), and this structure was included to emphasize with more dramatic etching that only the grain boundaries within the carburized layer reveal carbide precipitation (those in the substrate reveal only steps between grains rather than ditches where carbides used to be). In addition, this etching method also reveals the presence of a carbide phase that appears to cover perhaps the outer half of the hardened layer. 

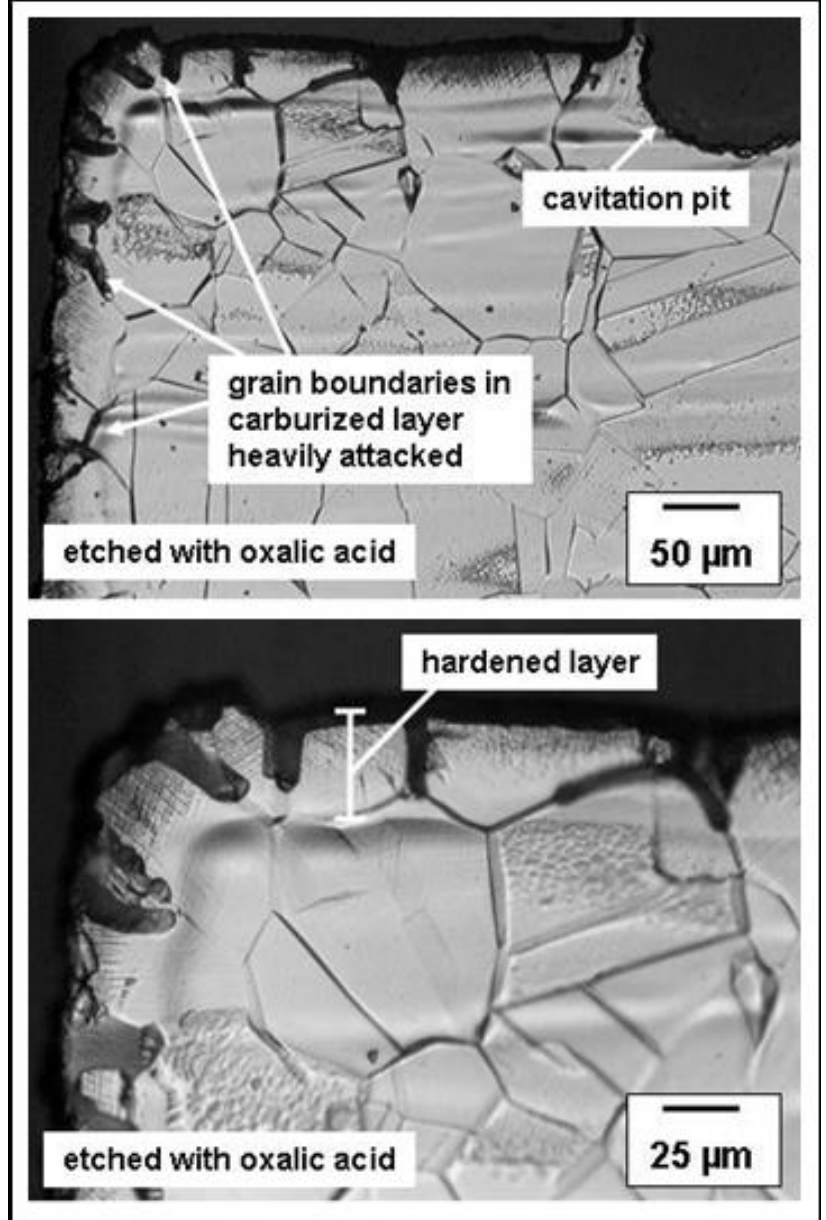

Fig. 10. Cross-section metallography (etched with oxalic acid) of the near surface region of the carburized specimen heat treated $60 \mathrm{~min}$ at $650^{\circ} \mathrm{C}$ prior to testing. 


\section{CONCLUSIONS}

The cavitation-erosion resistance of carburized 316LN stainless steel was significantly degraded — but not eliminated - by heat treatment in the temperature range $500-800^{\circ} \mathrm{C}$. The heat treatments caused rejection of some carbon from the carburized layer into an amorphous carbon-rich film that formed on each specimen surface. Further, the heat treatments encouraged carbide precipitation and reduced hardness within the carburized layer, but the overall change did not reduce hardness fully to the level of the untreated material (although heat treatment at $800^{\circ} \mathrm{C}$ resulted in hardness quite close to this level, substantial resistance to cavitation damage was retained). For specimens sonicated $6 \mathrm{~h}$ in mercury, heat treatment as short as $10 \mathrm{~min}$ at $650^{\circ} \mathrm{C}$ more than doubled the surface wastage (based on weight loss) compared to specimens receiving the same surface hardening but no subsequent heat treatment, and $60 \mathrm{~min}$ at $650^{\circ} \mathrm{C}$ resulted in a weight loss of about five times greater than specimens with no subsequent heat treatment. However, the latter treatment resulted in only about half the weight loss observed for annealed (no surface hardening) specimens. Heat treatment at 500 and $800^{\circ} \mathrm{C}$ was much less detrimental to cavitation-erosion performance of the carburized layer, but, particularly as assessed by crater formation and depth, these heat treatments were not without consequence in the vibratory horn tests. The results suggest that modest thermal excursions - perhaps the result of a weld made at some distance to the carburized material or a brief stress relief treatment - will not render the hardened layer completely ineffective but should be avoided to the greatest extent possible. 


\section{ACKNOWLEDGMENTS}

Thanks are due to B. Riemer, SNS Program Manager for Target Development activities, for providing encouragement, funding, and helpful discussions. W. Melvin (Bodycote Corporation) provided the carburized specimens for evaluation. A. Willoughby accomplished the heat treatments of these specimens within quartz containers fabricated by L. McCollum. H. Longmire (metallography), T. Brummett (SEM and limited microprobe data that was not documented in this report), and H. Meyer (X-ray photoelectron spectroscopy) also supported specimen analysis. Thanks also to J. DiStefano, J. Keiser, and P. Blau for helpful review of the manuscript, and A. Harkey for final preparation of this document.

Special thanks to Ms. Julia Hsu for participation in this effort through the Higher Education Research Experience Program of the Oak Ridge Institute for Science Education. Ms. Hsu was a senior at Farragut High School in Knoxville, Tennessee, at the time of her participation, which included primarily optical microscopy of specimen surfaces, SEM analysis, and hardness measurements.

\section{REFERENCES}

1. R. P. Taleyarkhan, F. Moraga, and C. D. West, p. 160 in Proceedings of the Second International Topical Meeting on Nuclear Applications of Accelerator Technology (AccApp98), Gatlinburg, TN, September 1998.

2. F. Moraga and R. P. Taleyarkhan, p. 301 in Proceedings of the Third International Topical Meeting on Nuclear Applications of Accelerator Technology (AccApp99), Long Beach, CA, November 1999.

3. R. V. DeMars, M. Siman-Tov, and R. P. Taleyarkhan, Trans. Am. Nuc. Soc. 76, 379 (1997).

4. K. Kikuchi et al., J. Nucl. Mater. 318, 84 (2003).

5. J. R. Haines et al., J. Nucl. Mater. 343, 58 (2005).

6. B. W. Riemer et al., J. Nucl. Mater. 318, 92 (2003).

7. J. D. Hunn, B. W. Riemer, and C. C. Tsai, J. Nucl. Mater. 318, 102 (2003).

8. B. W. Riemer et al., J. Nucl. Mater. 377, 162 (2008).

9. B. W. Riemer, M. W. Wendel, and D. K. Felde, J. Nucl. Mater. 398, 207 (2010).

10. R. Garcia, F. G. Hammitt, and R. E. Nystrom, "Correlation of Cavitation Damage with Other Material and Fluid Properties," p. 239 in Erosion by Cavitation or Impingement, ASTM STP 408, American Society for Testing and Materials, 1976.

11. M. D. Kass et al., Tribol. Lett. 5, 231 (1998). 
12. S. G. Young and J. R. Johnston, "Accelerated Cavitation Damage of Steels and Superalloys in Sodium and Mercury," p. 186 in Erosion by Cavitation or Impingement, ASTM STP 408, American Society for Testing and Materials, 1976.

13. S. J. Pawel and E. T. Manneschmidt, J. Nucl. Mater. 318, 122 (2003).

14. J. F. Grubb, “Corrosion of Wrought Stainless Steels," p. 59 in ASM Handbook, Volume 13B, Corrosion: Materials, ASM International, Metals Park, OH, 2005.

15. S. J. Pawel, J. Nucl. Mater. 343, 101 (2005).

16. S. J. Pawel and J. R. Nicholls, Preliminary Assessment of Multi-Layer TiB ${ }_{2}$ Cr Applied to Ti-Based Alloys to Improve Cavitation-Erosion Resistance in Mercury, Technical Memorandum ORNL/TM2009/141, Oak Ridge National Laboratory, May 2009.

17. K. Farrell et al., J. Nucl. Mater. 343, 123 (2005).

18. Standard Test Method for Cavitation Using Vibratory Horn Apparatus, ASTM G32-98, American Society for Testing and Materials, Philadelphia, PA, 1998, p. 109.

19. C. J. Novak, "Structure and Constitution of Wrought Austenitic Stainless Steels," in Handbook of Stainless Steels, D. Peckner and I. M. Bernstein, eds., McGraw-Hill, 1977, pp. 4-37.

20. Standard Practice for Preparing, Cleaning, and Evaluating Corrosion Test Specimens, ASTM G190, American Society for Testing and Materials, Philadelphia, PA, 1998. In particular, see solution C.7.5.

21. S. J. Pawel, Assessment of End-of-Life Behavior of the Surface Modification to Improve CavitationErosion Resistance in the Mercury Target at the Spallation Neutron Source, Technical Memorandum ORNL/TM-2007/063, Oak Ridge National Laboratory, June 2007.

22. S. J. Pawel, Assessment of Cavitation-Erosion Resistance of 316LN Stainless Steel Following a NitroCarburizing Surface Treatment, Technical Memorandum ORNL/TM-2009/287, Oak Ridge National Laboratory, November 2009. 